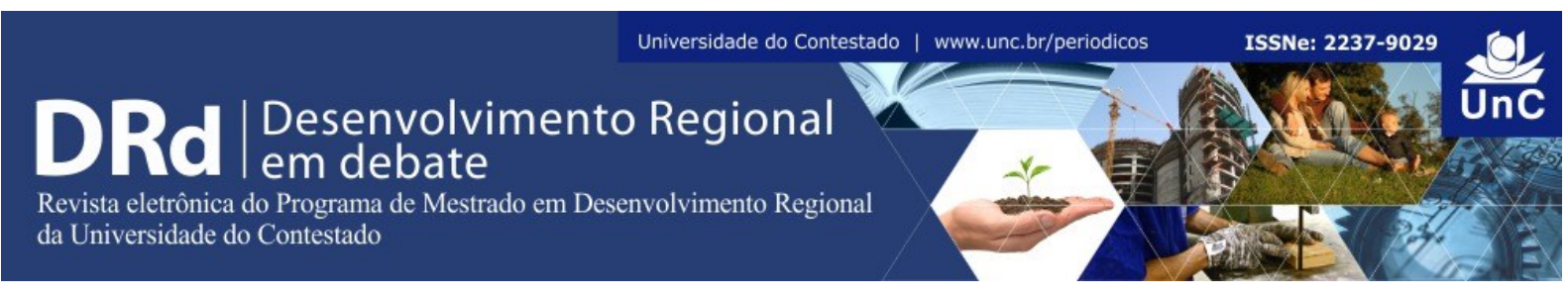

\title{
PLANALTO NORTE CATARINENSE: CONSIDERAÇÕES SOBRE O SETOR FLORESTAL E A EUCALIPTOCULTURA
}

\author{
Gisela Maria Pedrassani Andrejow ${ }^{1}$ \\ Daniela Pedrassani ${ }^{2}$ \\ Flávia Tussulini ${ }^{3}$ \\ Alessandro Camargo Angelo ${ }^{4}$ \\ Evandro Vagner Tambarussi ${ }^{5}$ \\ Celso Garcia Auer ${ }^{6}$
}

\begin{abstract}
RESUMO
A base econômica de florestas plantadas para a produção de madeira e seus produtos, sustenta uma cadeia produtiva que tem participação fundamental na economia do país. O Estado de Santa Catarina tem expressiva participação neste setor, tanto pelo número de empresas ligadas ao setor, como pela variedade e qualidade de produtos obtidos, sendo o Planalto Norte Catarinense (PNC) uma das regiões deste Estado onde o uso do solo com florestas plantadas se destaca. Neste contexto as florestas plantadas de Pinus e Eucalipto são a principal fonte de suprimento da cadeia produtiva florestal, abastecendo diversos segmentos industriais, suportando a economia de muitos municípios do PNC no cultivo de florestas. O objetivo deste trabalho consiste em compreender o papel do setor florestal e da eucaliptocultura como atividade econômica no PNC, analisando sua contribuição para a geração de empregos, produtos e renda, e a conservação dos recursos naturais, principalmente nas pequenas propriedades. O referencial teórico utilizado está associado aos conceitos e caracterizações fundamentais sobre setor florestal, florestas plantadas, cadeia produtiva do setor florestal, produção florestal e Planalto Norte Catarinense. Metodologicamente, o trabalho realizado classifica-se como pesquisa exploratória, para o que se utilizou de levantamento literário, com pesquisa bibliográfica e compilação de dados estatísticos obtidos em periódicos científicos, agências nacionais, estaduais e relatórios anuais de associações de classe. Os levantamentos efetuados identificaram contradição sobre os benefícios gerados em desenvolvimento econômico, social e ambiental que o setor de florestas plantadas pode ofecer às regiões onde está estabelecido. Considerando-se os três aspectos, destacam-se os indicadores de geração de renda e de empregos diretos e indiretos, a conservação do solo e da água, a captura de gases de efeito estufa e a conservação e preservação de florestas nativas. Como oportunidades ao desenvolvimento florestal sustentável do PNC estão as condições edáficas da região

\footnotetext{
${ }^{1}$ Doutoranda, Universidade Federal do Paraná, Av. Prefeito Lothário Meissner, 632 - Jardim Botânico, Curitiba. Paraná. Brasil. E-mail: gisela.andrejow@westrock.com

${ }^{2}$ Doutora, Programa de Mestrado em Desenvolvimento Regional da Universidade do Contestado. Santa Catarina. Brasil. E-mail: daniela@unc.br

Paraná. Brasil. E-mail: tussulini.f@gmail.com

${ }^{4}$ Doutor, Universidade Federal do Paraná, Av. Prefeito Lothário Meissner, 632 - Jardim Botânico, Curitiba.

Paraná. Brasil. E-mail: alessandrocangelo@gmail.com

${ }^{5}$ Doutor, Universidade Estadual do Centro-Oeste (UNICENTRO), Departamento de Engenharia Florestal, PR

153, Km 7, Irati, Paraná. Brasil. E-mail: tambarussi@gmail.com

${ }^{6}$ Doutor, Universidade Federal do Paraná, Av. Prefeito Lothário Meissner, 632 - Jardim Botânico, Curitiba.

Paraná. Brasil. E-mail: auer@cnpf.embrapa.br
}

${ }^{3}$ Graduanda, Universidade Federal do Paraná, Av. Prefeito Lothário Meissner, 632 - Jardim Botânico, Curitiba.
\end{abstract}

DRd - Desenvolvimento Regional em debate (ISSNe 2237-9029)

v. 8, n. 2, p. 143-168, jul./dez. 2018. 
favoráveis ao cultivo florestal e a previsão de consumo crescente de produtos florestais, inserindo a eucaliptocultura como atividade relevante nas políticas públicas e agenda de desenvolvimento regional.

Palavras-chave: Desenvolvimento regional. Santa Catarina. Setor Florestal. Eucalipto.

\title{
NORTHERN PLATEAU OF SANTA CATARINA: CONSIDERATIONS ON THE FOREST SECTOR AND EUCALYPTUSCULTURE
}

\begin{abstract}
The economic basis of forests planted for timber production and its products sustains a production chain that has a fundamental participation on the country's economy. The State of Santa Catarina has a significant participation in this sector, both by the number of companies linked to the sector, and by the variety and quality of products obtained, with North Plateau of Santa Catarina (NPofSC) being one of the regions of this State where the use of soil with planted forests stands out. In this context, planted forests of Pinus and Eucalyptus are the main supply source of the forestry production chain, supplying many industrial segments, giving support to many NPofSC counties in forest cultivation. The goal of this article consists on understanding the role of the forestry sector and the eucaliptus culture as economic activity at the NPofSC, analyzing its contribution for employment generation, products and income, the conservation and preservation of natural resources, focusing on the small properties. The theoretical reference used is associated to the fundamental concepts and characterization about the forestry sector, planted forests, production chain of the forestry sector, forest production and the North Plateau of Santa Catarina. Methodologically, the work done is classified as exploratory research, which used a literature survey, with bibliographic research compilation of statistic data obtained on scientific journals, national and state agencies, annual reports of class association. The data collected identified a contradiction in the benefits generated in economic, social and environmental development that the planted forests sector can offer to the regions where it is established. Considering these three aspects, stands out the income indicators as well as direct and indirect employment generation, the conservation of soil and water, the capture of greenhouse gases and the conservation and preservation of native forests. As opportunities to the sustainable forest development for the NPofSC, there are the climatic conditions that are favorable to the forest cultivation and the prediction of increasing forestry products consumption, inserting eucalyptus cultivation as a relevant activity in the public policies and regional development agenda.
\end{abstract}

Keywords: Regional Development. The Forestry Sector. Eucalyptus.

\section{INTRODUÇÃO}

O setor florestal brasileiro de florestas plantadas com uma área de 7,84 milhões de hectares de reflorestamento é responsável por $91 \%$ de toda a madeira produzida para fins industriais e $6,2 \%$ do PIB industrial do país, e é o segmento com maior potencial de 
contribuição para a construção de uma economia verde (IBA, 2017). No âmbito nacional, Santa Catarina possui a segunda maior área plantada em pinus (Pinus spp.) e uma área expressiva de florestas de eucalipto (Eucalyptus spp.). Contudo, grande parte da base florestal plantada de Santa Catarina está concentrada em empresas integradas verticalmente, garantindo o abastecimento de matéria-prima em seus processos industriais. Além das funções produtivas, o plantio de árvores pode desempenhar importante papel na prestação de serviços ambientais evitando o desmatamento de hábitats naturais, protegendo assim a biodiversidade. Cabe salientar que florestas são fontes de energia renovável e contribuem para a redução das emissões de gases causadores do efeito estufa por serem estoques naturais de carbono, e utilizando-se espécies corretas com manejo adequado podem auxiliar na recuperação de áreas degradadas, preservando o solo e as nascentes de rios (IBA, 2016).

Pode-se destacar ainda, que as atividades de base florestal nos municípios são realizadas em áreas de menor índice de desenvolvimento Humano (IDH), incluindo na cadeia produtiva a participação dos pequenos e médios produtores. Assim sendo, municípios nos quais o setor florestal atua, podem apresentar oportunidades de trabalho e geração de riqueza, participando do desenvolvimento regional sustentável, a partir do cultivo de árvores plantadas como alternativa econômica e ambientalmente viável.

Apesar de o setor de florestas plantadas ser fortemente consolidado no país, ainda existem poucos dados estatísticos oficiais e as informações sobre o setor florestal são bastante conflitantes, demonstrando apenas de maneira macro a localização e distribuição dos cultivos florestais (COUTINHO et al., 2017), pois, as informações consideradas são disponibilizadas pelos relatórios anuais de associações de classe.

Esses aspectos nortearam a compilação deste artigo, explorando informações do setor florestal e da eucaliptocultura no tangente ao Planalto Norte do Estado de Santa Catarina, cujas características edafoclimáticas favoráveis ao seu rápido crescimento e alta produtividade, tem relevância para o desenvolvimento econômico, social e ambiental. $\mathrm{O}$ objetivo deste trabalho consiste em compreender o papel do setor florestal e da eucaliptocultura como atividade econômica no PNC, analisando sua contribuição para a geração de empregos, produtos e renda, e a conservação dos recursos naturais, principalmente nas pequenas propriedades. As informações deste trabalho podem fornecer subsídios aos formuladores de políticas e de agendas de desenvolvimento da região, alavancando a eucaliptocultura considerando os aspectos ambientais, sociais e econômicos.

\section{REFERENCIAL}

\subsection{SETOR FLORESTAL}

A área de florestas plantadas representa $0,9 \%$ do terrirório brasileiro, que possui aproximadamente 8,5 milhões de $\mathrm{km}^{2}$ (7,84 milhões de hectares) no total. $\mathrm{O}$ plantio de florestas registrou crescimento de $0,5 \%$ no ano de 2016 em relação ao ano 2015, devido exclusivamente ao aumento das áreas cultivadas com eucalipto (IBA, 2016, 2017). 
No Brasil, os plantios de florestas começaram há mais de um século. Em 1903, o pioneiro Navarro de Andrade trouxe mudas de eucalipto para plantios que produziriam madeira para dormentes das estradas de ferro e de acordo com o Boletim SNIF (2016) em 1947 foi a vez do pinus.

Em IBA (2017, p. 31) cita-se que "a maior concentração de área reflorestada encontrase nas regiões sul e sudeste. Santa Catarina detém o total de 662 mil hectares com florestas plantadas. É o $5^{\circ}$ estado com maior área plantada no Brasil sendo que a grande maioria (82\%, ou equivalente a 545,8 mil ha) é com Pinus, e 17,5\% (116,2 mil ha) com eucalipto" (Figura $1)$.

Figura 1 - Distribuição das árvores plantadas por estado e espécie.

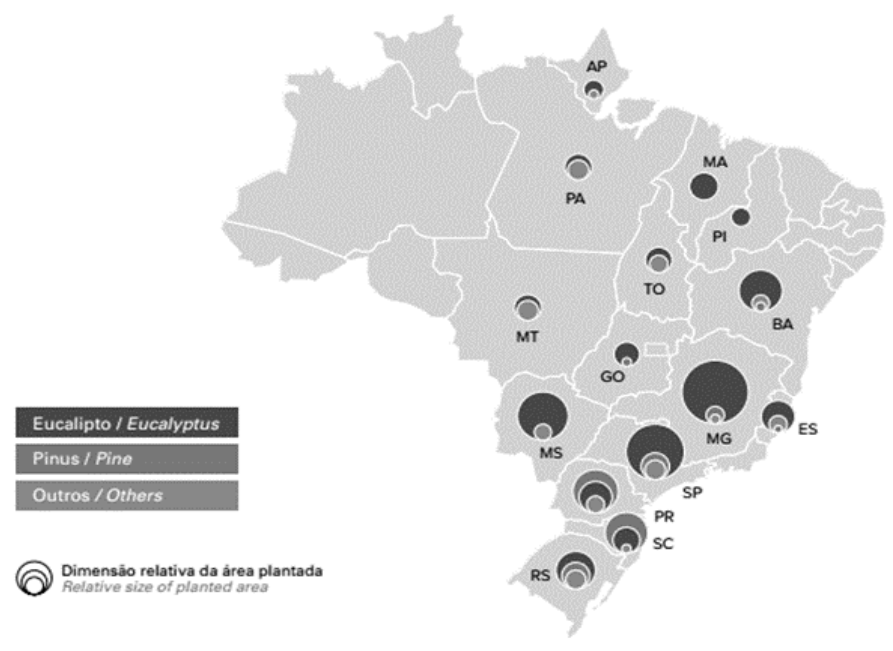

\begin{tabular}{|c|c|c|}
\hline \multicolumn{3}{|c|}{$\begin{array}{c}\text { Área plantada com árvores (ha) } \\
\text { Area of planted trees }\end{array}$ (ha) } \\
\hline $\begin{array}{c}\text { Estado } \\
\text { State }\end{array}$ & $\begin{array}{c}\text { Eucalipto } \\
\text { Eucalyptus }\end{array}$ & $\begin{array}{c}\text { Pinus } \\
\text { Pine }\end{array}$ \\
\hline MG & 1.390 .032 & 36.764 \\
SP & 946.124 & 124.179 \\
MS & 877.124 & 5.852 \\
BA & 612.199 & 3.301 \\
RS & 308.178 & 184.595 \\
ES & 233.760 & 2.500 \\
PR & 294.050 & 672.607 \\
MA & 221.859 & - \\
MT & 185.219 & - \\
PA & 133.996 & - \\
GO & 127.201 & 8.500 \\
TO & 116.798 & 200 \\
SC & 116.240 & 545.835 \\
AP & 65.026 & - \\
PI & 26.086 & - \\
Outras & 19.239 & - \\
Others & & \\
\hline Total & $\mathbf{5 . 6 7 3 . 7 8 3}$ & $\mathbf{1 . 5 8 4 . 3 3 2}$ \\
\hline
\end{tabular}

Fonte: IBA, 2017.

Concomitantemente à expansão da área de florestas plantadas, fortes críticas foram lançadas, uma vez que o eucalipto era visto como uma árvore exótica danosa as espécies florestais nativas e ao meio ambiente (PAYRET, 2007), entretanto com o passar dos anos, estudos científicos revelaram que o eucalipto pode trazer benefícios de cunho social e ambiental, opondo-se ao que era conjeturado (BROCKERHOFF et al., 2012). Somado a isso, observa-se o engajamento de diversas empresas do setor florestal em projetos sociais e de conservação da biodiversidade, com as ações de diagnóstico e monitoramento de fauna e flora (GOMES et al., 2006).

De acordo com Moreira et al. (2017), o segmento de florestas plantadas destaca-se no Brasil pelo seu elevado impacto social e econômico. A atividade apresenta alto potencial de expansão, com geração de renda e emprego, principalmente ao longo da sua cadeia produtiva de transformação da madeira, incrementando a obtenção líquida de divisas para o país. Porém a área de plantio é ainda pouco explorada em relação ao seu potencial produtivo e à disponibilidade de terras para cultivos florestais. Neste aspecto, áreas com florestas plantadas cumprem papel altamente determinante no abastecimento de matéria-prima para a indústria de transformação, contribuindo diretamente com o desenvolvimento econômico (ACR, 2016). 


\subsection{FLORESTAS PLANTADAS}

Para a Organização das Nações Unidas para Agricultura e Alimentação (FAO), a definição de florestas é que esta corresponde a "[...] uma área medindo mais de 0,5 ha com árvores maiores que $5 \mathrm{~m}$ de altura e cobertura de copa superior a $10 \%$, em relação a sua altura; ou árvores capazes de alcançar estes parâmetros in situ excluindo-se terra que está predominantemente sob uso agrícola ou urbano" (FRA, 2015, p. 3). A grande demanda de madeira para diferentes finalidades (serraria, laminação, carvão e celulose) vem contribuindo para o desenvolvimento do setor florestal e das comunidades rurais, uma vez que o cultivo de florestas de eucalipto permite a todos os tipos de agricultores a diversificação de renda na propriedade, seja por meio de plantios puros (bosquetes), seja por meio de sistemas integrados de produção, como os sistemas silvipastoris, por exemplo (SANTAROSA et al., 2014). Neste contexto, o Estado de Santa Catarina apresenta enorme potencial produtivo para expandir a área plantada considerando-se as pequenas propriedades, pois segundo dados da Empresa de Pesquisa Agropecuária e Extensão Rural de Santa Catarina, Epagri (2016), ao todo no Planalto Norte existem cerca de 12.871 propriedades com menos de 50 hectares.

Os plantios com pinus e eucalipto no Estado estão concentrados principalmente na região serrana (Figura 2), com destaque para os municípios de Santa Cecília, Lages e Otacílio Costa, que juntos detém cerca de 100 mil hectares plantados, principalmente com pinus. As regiões oeste (Caçador) e norte do estado (Rio Negrinho e Mafra), também sobressaem pela grande concentração de plantios florestais (ACR, 2016).

Figura 2 - Localização esquemática dos principais municípios do Estado de Santa Catarina com floresta plantada de Pinus e Eucaliptos.

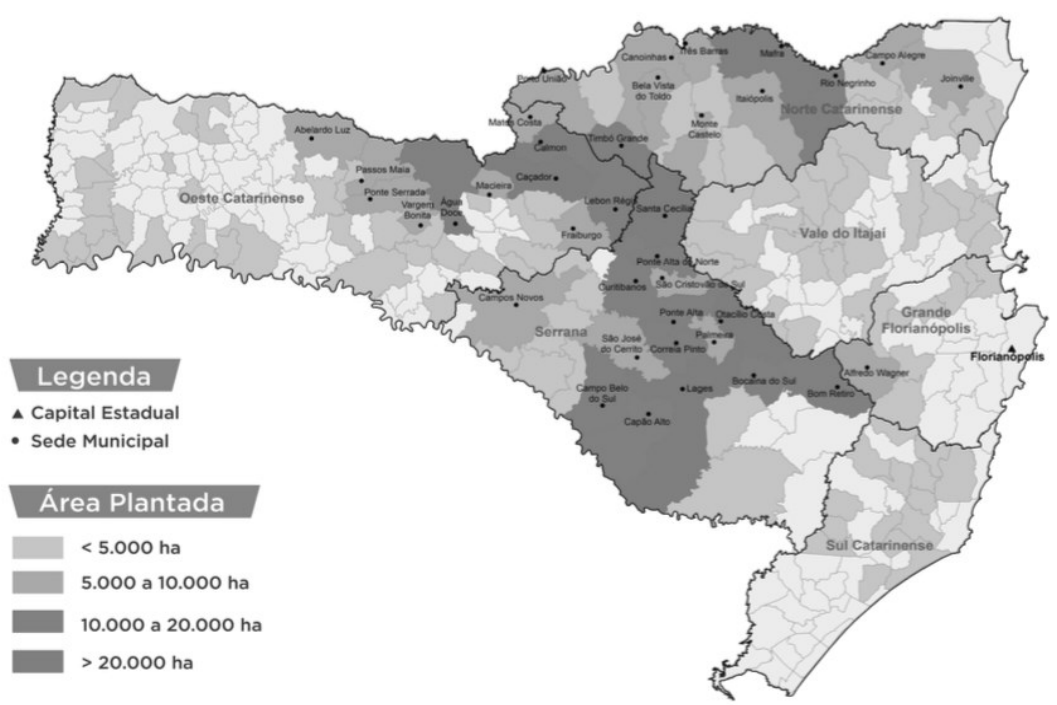

Fonte: ACR, 2016.

O Eucalyptus é um gênero originário da Austrália, e atualmente são mais de 700 espécies catalogadas botanicamente (SANTAROSA et al., 2014). Por volta do início do século XX a cultura de eucalipto encontrou oportunidades de se consolidar como floresta 
plantada no Brasil devido a sua madeira de grande potencial de uso (SANTAROSA et al., 2014). Um dos problemas da introdução do gênero em outros países é a seleção inicial de espécies, correlacionando com as condições edafoclimáticas (relação espécie-solo-clima para plantio), e finalidade de uso. Porém, não mais que 20 delas são atualmente utilizadas para fins comerciais em todo o mundo de acordo com Santarosa et al. (2014). Estima-se que os plantios de eucalipto ocupam 5,7 milhões de hectares da área de árvores plantadas no País, o que representa 72,3\% do total, sendo em Santa Catarina 116.240 ha (IBA 2017). As condições climáticas do Planalto Norte Catarinense, com ocorrência de baixas temperaturas e geadas, limitam a esta escolha da espécie adequada a ser plantada, restando Eucalyptus dunnii e Eucalyptus benthamii, como espécies com potencial madeireiro e entre os principais usos comerciais cita-se a matéria-prima para a fabricação de celulose e papel e como fonte de biomassa para combustível.

\subsection{PLANALTO NORTE CATARINENSE (PNC)}

Tomporoski e Marchesan (2016, p. 53) descrevem a delimitação do PNC:

O Planalto Norte Catarinense possui uma área territorial de $11.041,365 \mathrm{~km}^{2}$ (onze mil, quarenta e um vírgula trezentos e sessenta e cinco quilômetros quadrados), representando $11,58 \%$ (onze inteiros e cinquenta e oito centésimos por cento) da área territorial do estado de Santa Catarina, e é constituído por 13 (treze) municípios, a seguir enumerados, em ordem alfabética: Bela Vista do Toldo, Campo Alegre, Canoinhas, Irineópolis, Itaiópolis, Mafra, Major Vieira, Monte Castelo, Papanduva, Porto União, Rio Negrinho, São Bento do Sul, Três Barras.

Na figura 3 são apresentados geograficamente os municípios que integram o Planalto Norte Catarinense sob a perspectiva do Estado de Santa Catarina e do Brasil.

Figura 3 - Localização dos municípios do Planalto Norte Catarinense sob a perspectiva do Estado de Santa Catarina e da República Federativa do Brasil.

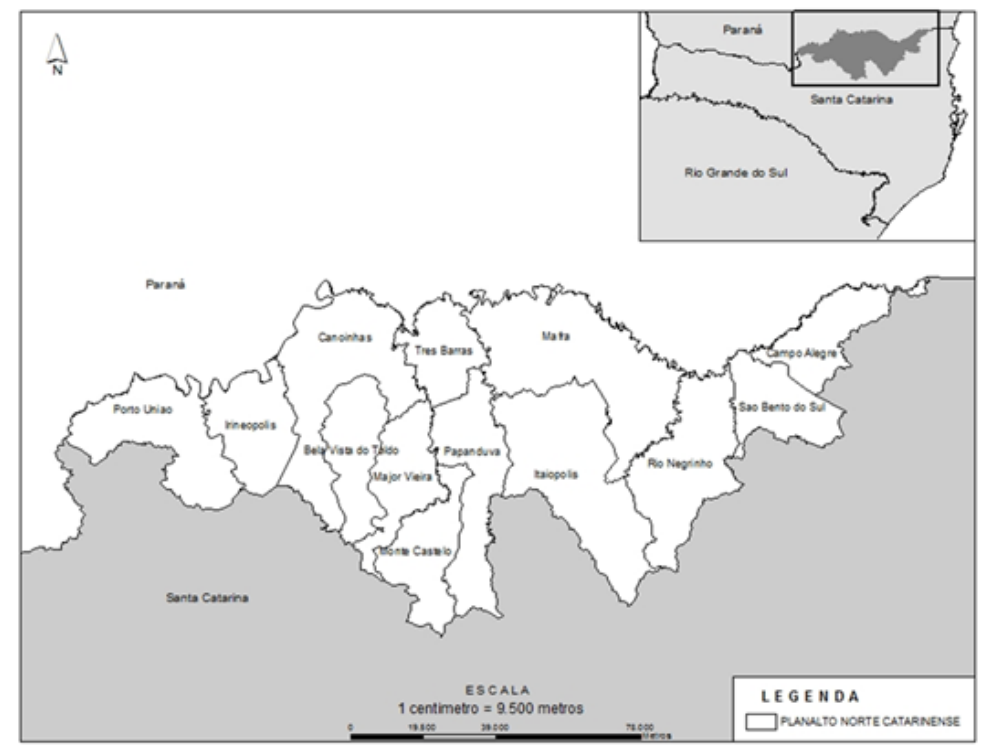

Fonte: Elaborado pelos autores, 2017.

DRd - Desenvolvimento Regional em debate (ISSNe 2237-9029)

v. 8, n. 2, p. 143-168, jul./dez. 2018. 
A atividade econômica regional tem se concentrado na cadeia produtiva de base florestal, compreendendo a produção florestal, produtos de madeira, artigos de mobiliário e celulose-papel, sendo Canoinhas, Mafra, Porto União e São Bento do Sul os maiores centros urbanos (PORTAL DA ECONOMIA DE SANTA CATARINA, 2017). De acordo com Moreira et al. (2016), depois de analisarem os indicadores socioeconômicos, os autores afirmaram que os municípios do PNC apresentam extrema dependência do setor agropecuário, destacando-se o plantio de espécies vegetais exóticas, entre elas o eucalipto, para a indústria papeleira, esta mais representativa na região, ocupando extensas áreas com monoculturas silvícolas.

Para Dallabrida et al. (2011 apud DALLABRIDA, 2014, p. 47):

O território é uma construção social resultante de relações de poder que, simultaneamente, contém a dimensão da unidade, da solidariedade e da conflitualidade. Trata-se de relações inseridas na história de uma sociedade situada territorialmente. Refere-se a uma fração do espaço, historicamente construída pelas interelações dos atores sociais, econômicos e institucionais que atuam neste recorte espacial, apropriada a partir de relações de poder sustentadas em motivações políticas, sociais, econômicas, culturais ou religiosas, oriundas do Estado, de grupos sociais ou corporativos, instituições ou indivíduos.

O conceito para definição de região e território é distinto. Entretanto para mensurar o desenvolvimento de determinada região, é imprescindível a compreensão de que o tema envolve "duas categorias de fatores de análise: uma objetiva, baseada em indicadores econômicos de fácil mensuração e outra subjetiva que abarca outros fatores que nem sempre são mensuráveis através de dados estatísticos" como cita Moreira et al. (2016, p. 89).

\subsection{CADEIA PRODUTIVA DO SETOR FLORESTAL}

A cadeia produtiva com base no setor florestal constitui uma atividade econômica complexa e diversificada de produtos e aplicações energéticas e industriais (SNIF, 2017), podendo ser subdividida em insumos madeireiros e não madeireiros, conforme Figura 4 e que representa os principais elos entre a floresta, indústria e o mercado. 
Figura 4 - Cadeia produtiva do setor florestal no Brasil

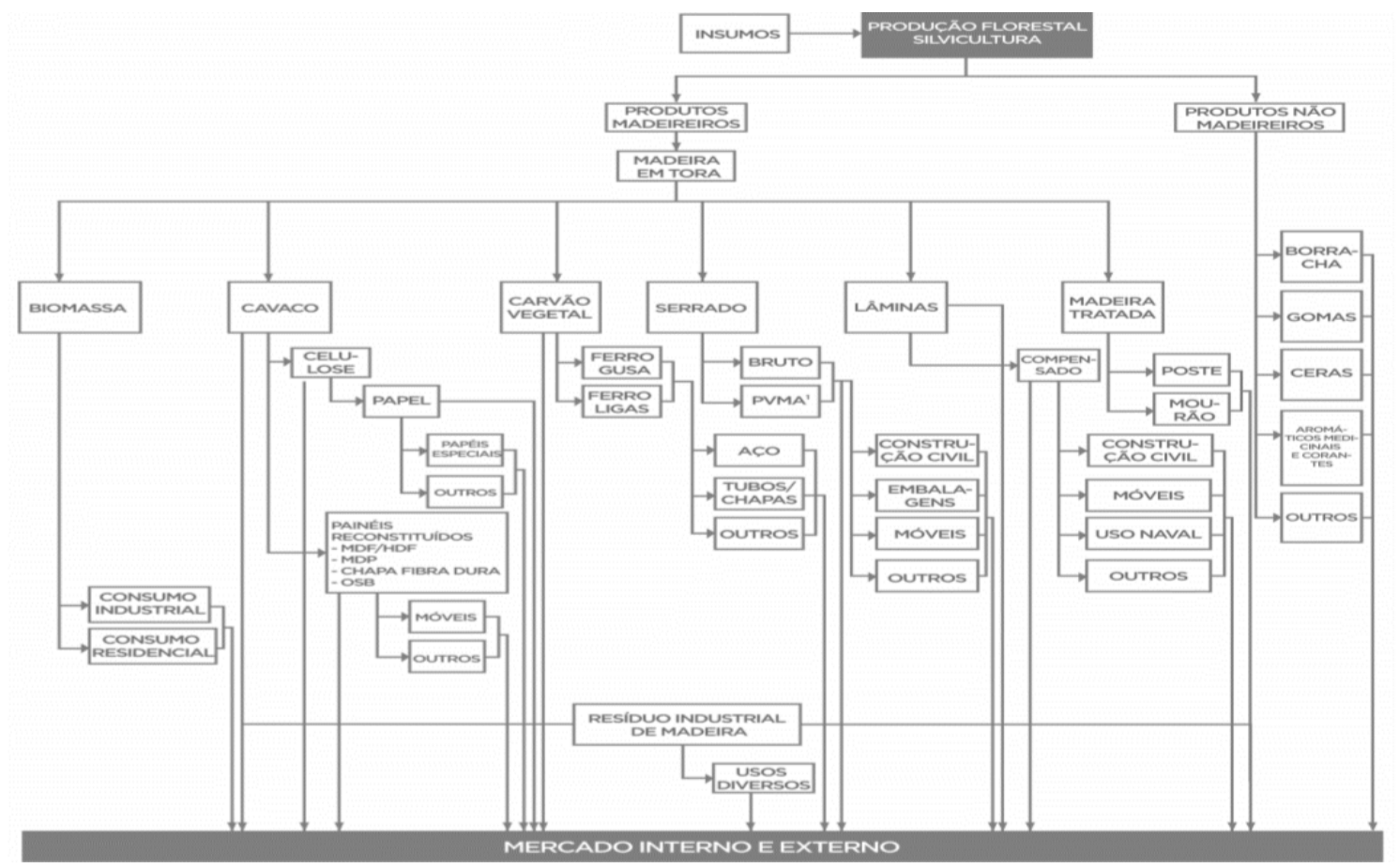

Fonte: ACR, 2016.

De acordo com o Sistema Nacional de Informações Florestais (SNIF, 2017, p. 1), “[...] cadeia produtiva é um conjunto de etapas consecutivas pelas quais passam e vão sendo transformados e transferidos os diversos insumos desde a pré-produção até o consumo final de um bem ou serviço". Trata-se de atividade econômica complexa e com diversidade de produtos que podem ser comercializados em qualquer ponto da exploração florestal ou nível de processamento industrial. A dinâmica do setor florestal, desde a inserção dos insumos para a produção florestal, passando por diversos produtos na indústria até chegar aos pontos de comercialização, representados aqui pelo mercado nacional e internacional, observado na figura 4 (ACR, 2016).

Para a ABRAF (2013), há três modelos de organização industrial. O primeiro integra empresas verticalizadas, elas são consumidoras de matéria-prima própria e geralmente têm equipe própria para as operações florestais, de modo a garantir a qualidade da matéria-prima que será consumida na fábrica. $\mathrm{O}$ segundo são os produtores independentes, proprietários de terra (pequenos e médios produtores) que investem em plantios florestais como fonte de renda a partir da comercialização da madeira roliça. E, enfim, o terceiro, o Timber Investiment Managent Organizations (TIMOs), que são empresas de gestão de investimentos florestais, vinculados ou não aos fundos de pensão estrangeiros. Estas adquirem ativos florestais e fazem a intermediação entre investidores e os consumidores de madeira de florestas plantadas (ABRAF, 2013). As empresas verticalizadas podem ser divididas em segmentos industriais, conforme Quadro 1. 
Quadro 1 -Segmentos Industriais brasileiros, seus principais produtos e destino final.

\begin{tabular}{|c|c|c|}
\hline Segmento & Principais Produtos & Consumo Final \\
\hline Papel e Celulose & $\begin{array}{l}\text { Celulose, papéis para escrever; embalagens; } \\
\text { papel cartão; papéis sanitários. }\end{array}$ & $\begin{array}{l}\text { Gráficas; editoração; embalagens; } \\
\text { consumo industrial e doméstico }\end{array}$ \\
\hline $\begin{array}{l}\text { Painéis de Madeira } \\
\text { Industrializada }\end{array}$ & $\begin{array}{c}\text { MDF, aglomerados, chapas de fibra, OSB; } \\
\text { HDF; lâminas }\end{array}$ & $\begin{array}{l}\text { Móveis; componentes para móveis; } \\
\text { construção civil }\end{array}$ \\
\hline $\begin{array}{l}\text { Processamento } \\
\text { Mecânico }\end{array}$ & $\begin{array}{l}\text { Madeira serrada; vigas; tábuas PMVA; } \\
\text { pranchas; ripas; sarrafos; compensados }\end{array}$ & $\begin{array}{l}\text { Móveis; componentes para móveis; } \\
\text { construção civil; embalagens; uso naval }\end{array}$ \\
\hline Madeira Tratada & $\begin{array}{c}\text { Mourões; postes; cruzetas; pilares; cercas; } \\
\text { muros; dormentes }\end{array}$ & Construção civil e infraestrutura \\
\hline $\begin{array}{l}\text { Siderurgia e Carvão } \\
\text { Vegetal }\end{array}$ & Ferro gusa, ferro liga; aço & $\begin{array}{c}\text { Construção civil; indústria de automóveis } \\
\text { e de eletrodoméstico }\end{array}$ \\
\hline Energia & Lenha industrial; biomassa; pallets & Consumo industrial e doméstico \\
\hline
\end{tabular}

Fonte: ABRAF, 2013.

\subsection{A PRODUÇÃO FLORESTAL}

Existe uma elevada utilização da matéria-prima, que são os produtos florestais madeireiros (PFM) e não madeireiros (PFNM); por parte da indústria de base florestal. Segundo definições utilizadas pelo SNIF (2016) tem-se Produto Florestal Madeireiro (PFM) é todo o material lenhoso passível de aproveitamento para: serraria, estacas, lenha, poste, moirão, etc...; Produto Florestal Não Madeireiro (PFNM) é todo o produto florestal não lenhoso de origem vegetal, tais como resina, cipó, óleo, sementes, plantas ornamentais, plantas medicinais, bem como serviços sociais e ambientais, como reservas extrativistas, sequestro de carbono, conservação genética e outros benefícios oriundos da manutenção da floresta. Produção é a atividade de transformação (processo) de matéria-prima em bens de consumo (produtos). Na produção florestal, a matéria-prima pode ser proveniente de florestas plantadas ou de florestas naturais.

A vocação da região sul para o cultivo de florestas plantadas, concentrando empresas produtoras de produtos madeiros (Figura 5), destaca-se pelo elevado grau de aproveitamento da matéria-prima através de produtos florestais madeireiros (PFM) na referida região fortemente representado pela tora. 
Figura 5 - Distribuição geográfica das empresas produtoras de celulose e papel (1), Painéis de madeira reconstituída (2).
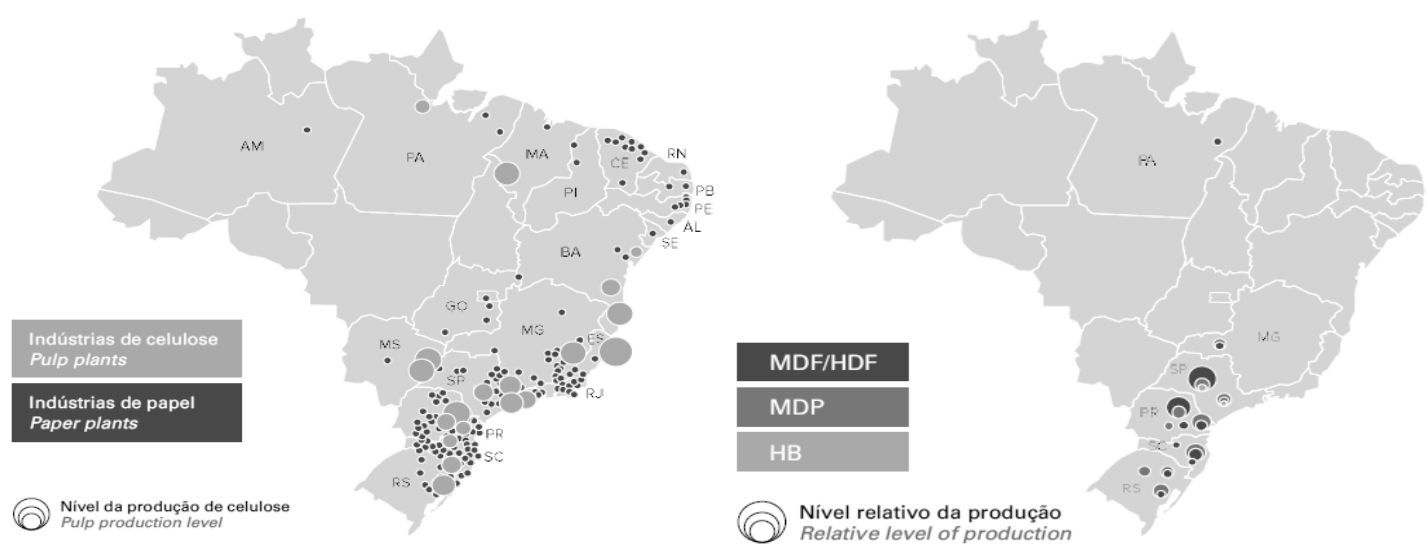

Fonte: IBA, 2017.

Devido ao seu potencial econômico, resultado de um crescimento rápido e versatilidade quanto à adaptação em diferentes regiões, o eucalipto tem a preferência do setor em sua utilização em plantios florestais (SANTAROSA et al., 2014). A alta produtividade de madeira, em ciclos de corte de aproximadamente sete anos, com menores custos e maiores taxas de retorno do investimento, conferem grande atratividade ao cultivo do eucalipto, garantindo alta competitividade de seus produtos nos mercados interno e externo (SANTAROSA et al., 2014). A diversidade de produtos desta complexa atividade econômica oferece produtos que podem ser comercializados em qualquer nível de processamento industrial ou ponto da exploração florestal. Os dados do quadro 2, exemplificam preferência de uso da madeira do eucalipto nos diversos segmentos da indústria de base florestal.

Quadro 2 - Consumo de madeira no Brasil para uso industrial por segmento e gênero.

\begin{tabular}{|l|c|c|c|c|}
\hline \multicolumn{1}{|c|}{ Segmento } & \multicolumn{4}{c|}{ Milhões de $\mathrm{m}^{3}$} \\
\cline { 2 - 5 } & Eucalipto & Pinus & Outras & Total \\
\hline Celulose e Papel & 70,74 & 9,25 & 0,09 & 80,07 \\
\hline Painéis reconstituídos & 5,93 & 6,70 & 0,37 & 12,99 \\
\hline Indústria madeireira & 5,86 & 27,37 & 0,35 & 33,58 \\
\hline Carvão & 21,46 & - & - & 21,46 \\
\hline Lenha Industrial & 46,94 & 3,72 & 4,31 & 54,98 \\
\hline Madeira Tratada & 1,46 & - & - & 1,46 \\
\hline Outros & 1,57 & 0,15 & - & 1,71 \\
\hline Total & 153,96 & 47,19 & 5,12 & 206,25 \\
\hline
\end{tabular}

Fonte: IBA, 2017.

Bernardino (2015) comenta que o desafio do Brasil é utilizar o recurso florestal explorando todo o potencial da floresta, utilizando seus bens e serviços renováveis, deixando de caminhar em paralelo com o desenvolvimento, pois as atividades florestais tem vantagens 
competitivas e são estratégicas para o desenvolvimento do país. Com esta visão, entender a cadeia produtiva do setor florestal e seus produtos, é primordial para gerar oportunidades de integrar desenvolvimento e sustentabilidade ao cultivo de florestas.

Segundo dados de Li e Lui (2010), em uma região ao sul da China a cultura de eucalipto trouxe benefícios socioeconômicos, porém também acarretou em problemas ambientais, especialmente se mal manejado. Algumas desvantagens apresentadas foram a redução da biodiversidade, o que levou consequentemente à erosão do solo e deterioração ecológica. Na questão de fertilidade do solo, é aconselhável que seja deixada a biomassa para adição de nutrientes e retenção da umidade. Igualmente, um estudo realizado por Daba (2016) retrata o dilema do plantio de eucalipto na Etiópia, analisando os benefícios sócio econômicos e os impactos ambientais do mesmo. O rápido crescimento, boa qualidade da madeira e fibras, produção de sementes e versatilidade de crescimento em várias regiões, torna o eucalipto uma espécie alvo de plantio, especialmente com o crescimento populacional. Entretanto, existem indicações de desvantagens quanto ao uso desta espécie devido à alta taxa de evapotranspiração que altera o microclima, alta demanda por água e nutrientes, que podem ser minimizados pela escolha correta do local e da espécie deste gênero.

\subsection{INDICADORES ECONÔMICOS, SOCIAIS E AMBIENTAIS}

As florestas plantadas foram responsáveis pela geração de $\mathrm{R} \$ 11,4$ bilhões em tributos federias, estaduais e municipais em 2016, correspondente a 0,9\% da arrecadação do País. $\mathrm{O}$ PIB setorial alcançou $\mathrm{R} \$ 71,1$ bilhões e a receita proveniente das exportações do setor atingiu US\$ 8,9 bilhões de acordo com IBA (2017). O setor em 2016 empregou 510 mil pessoas diretamente nas atividades, estimando-se que os postos de trabalho diretos, indiretos e resultantes do efeito renda, tenha sido da ordem de 3,7 milhões (IBA, 2017). O setor envolve mais de 60 mil empresas que dependem direta e/ou indiretamente do produto madeira (SANTAROSA et al., 2014).

Os plantios florestais apresentam-se em sua maior parte como monoculturas. Entretanto, as pesquisas têm avançado na área de sistemas agroflorestais e silvipastoris que tem demonstrado resultados positivos nos aspectos econômicos, ambientais e sociais (FLORESTAL, 2017).

O PNC em 2015 contava com uma população total de 357.200 habitantes (IBGE, 2017). De acordo com Sistema De Informações Territoriais - SIT (2017), nesta região concentra-se 3,6\% da população do Estado, dos quais 23,64\% vivem na área rural. Possui 12.909 agricultores familiares, 460 famílias assentadas e duas terras indígenas. O IDH regional em 2010 era de 0,724, tendo o município de Porto União com 0,786, o mais alto e Monte Castelo, que apresenta o IDH mais baixo de 0,675 (IBGE, 2017). A maior parcela da mão de obra industrial da região está no segmento produtor de móveis e a segunda atividade que mais emprega é a madeireira (ECONOMIA SC, 2011).

Moreira et al. (2016) analisando indicadores socioeconômicos para os municípios do PNC identificaram que estes são extremamente dependentes do setor agropecuário, destacando o plantio de espécies exóticas como a mais representativa, imobilizando extensões 
de terra com monocultura silvícola. As florestas plantadas poderiam, pela sua produção e uso de forma responsável, suprir as necessidades socioambientais fundamentais ao desenvolvimento sustentável pois são importante fonte de matéria prima para a indústria de base florestal, sendo um recurso natural renovável e durável, que ao mesmo tempo é rentável e ambientalmente necessário. Sendo assim, com Bernardino (2015, p. 58) “[...] agrossilvicultura com eucalipto aparece como uma alternativa para o desenvolvimento florestal sustentável [...]”.

\section{MATERIAL E MÉTODOS}

A fim de realizar esta revisão bibliográfica, foi utilizado o método de análise descritiva, de forma a expor características do assunto relatado, e o método de pesquisa exploratório, com objetivo de apresentar construções de hipóteses e novos pontos de vista. Os dados foram elaborados por meio de informações disponibilizadas por agências nacionais e relatórios anuais de associações de classe. Informações para auxiliar a interpretação, foram obtidas de literatura científica disponível sobre o tema proposto.

Com todos os dados obtidos a partir das referências, as informações foram conglomeradas para que fosse explorado o potencial da eucaliptocultura no Planalto Norte Catarinense para pequenos e médios produtores.

As informações acerca do uso do solo e dos cultivos agrosilvopastoris e outras atividades executadas no meio rural apresentadas são resultado do censo agropecuário, realizado em todos os municípios brasileiros no ano de 2006 com dados obtidos do site IBGE (IBGE, 2017). Outros dados foram extraídos do acervo do site IBGE cidades (2017). A base de dados foi exportada para planilhas editáveis e foram confeccionados os gráfícos correspondentes às informações apresentadas.

\section{RESULTADOS E DISCUSSÃO}

\subsection{A IMPORTÂNCIA DO SETOR FLORESTAL PARA SANTA CATARINA}

A economia catarinense cresceu, em grande parte devido à exploração madeireira registrada no século XX e de acordo com Tomporoski e Marchesan (2016, p. 62) "[...] portanto, o processo extrativista de produção, deflagrado pelo capital estrangeiro nas primeiras décadas do século XX, ainda hoje exerce influência sobre o desenvolvimento do território do Planalto Norte Catarinense", igualmente Dallabrida e Milani (2016, p. 31) enfatizam que no PNC "[...] nas últimas décadas ocorreu a substituição de culturas nativas, tais como, a araucária e a erva-mate, por monoculturas silvícolas (pinus e eucalipto) [...]”. 
Neste cenário, de acordo com dados de 2014 da ACR, são 14.821 empresas do setor florestal, das quais $47 \%$ são indústrias madeireiras, $43 \%$ são indústrias de móveis, 5\% no ramo da silvicultura e 3\% indústrias de papel e celulose, que empregaram diretamente cerca de 92.616 pessoas. Dos empregos formais do Setor Florestal-Madeireiro de Santa Catarina em 2014, 32.106 (35\%) estão concentrados nos seguintes municípios em ordem de importância: Caçador, São Bento do Sul, Lages, Rio Negrinho, Três Barras, Santa Cecília, Mafra, Blumenau, Canoinhas e Otacílio Costa, sendo cinco deles do PNC (ACR, 2016).

$\mathrm{O}$ ordenamento da atividade florestal do Estado Catarinense, segundo o Anuário Estatístico de SC, 2016 (ACR, 2016), apresenta-se da seguinte maneira:

$-5^{\circ}$ Estado em área de florestas plantadas, com 662 mil hectares;

$-2^{\circ}$ Estado em área plantada de pinus, com 541 mil hectares;

$-4^{\mathrm{o}}$ Produtor de toras, com $10 \%$ da produção brasileira de toras;

$-3^{\circ}$ Exportador de papéis com $12 \%$ da exportação brasileira;

$-1^{\circ}$ Exportador de madeira serrada com $44 \%$ da exportação brasileira;

$-2^{\circ}$ Exportador brasileiro de compensados com $26 \%$ da exportação brasileira;

$-3^{\circ}$ Exportador de painéis reconstituídos com $12 \%$ da exportação brasileira;

$-1^{\circ}$ Exportador de portas de madeira com $75 \%$ da exportação brasileira;

$-1^{\circ}$ Exportador de móveis de madeira com $44 \%$ da exportação brasileira.

-É o maior exportador de molduras de madeira com 99,9\% da exportação brasileira.

Neste contexto, evidencia-se a importância das florestas plantadas, particularmente com espécies de alta produtividade e ciclos curtos, como o eucalipto, com a finalidade da sustentabilidade ao desenvolvimento do estado suprindo a demanda do setor madeireiro.

\subsection{INDICADORES ECONÔMICOS DO SETOR FLORESTAL EM SANTA CATARINA}

O PIB do setor de florestas plantadas alcança R $\$ 3,7$ bilhões, ou seja, 3\% do PIB do Estado. São Bento do Sul é a maior cidade em população e em participação no PIB (ECONOMIA SC, 2011). Em 2015 Santa Catarina exportou US\$ 7,6 bilhões respondendo por $4 \%$ do total nacional. O setor florestal-madeireiro do estado participou com cerca de $10 \%$ ou US\$ 1,0 bilhão do total nacional de US\$10,3 bilhões (ACR, 2016). Com base nos dados da Confederação Nacional da Indústria, 543 empresas estabelecidas em Santa Catarina 
realizaram exportações de produtos do setor madeireiro e moveleiro em 2008, fato que consolida Santa Catarina entre os principais Estados exportadores (SEBRAE, 2010).

O Estado detém mais de 35 importantes empresas que atuam no setor de base florestal e dados do Anuário Estatístico de Base Florestal -2016 mostram que o segmento gerou mais de 92 mil empregos diretos para os catarinenses (ACR, 2016). No setor florestal, atuam em Santa Catarina 31 fábricas de papel, cinco de celulose e 10 de pastas de alto rendimento. Para o setor moveleiro, o principal polo produtor se localiza no Planalto Norte, concentrando cerca de 250 empresas em Rio Negrinho, São Bento do Sul e Campo Alegre, empregando diretamente cerca de 11 mil trabalhadores (FIESC, 2014).

O segmento de florestas plantadas destaca-se no Sul do Brasil pelo seu elevado impacto social e econômico. A atividade apresenta alto potencial de expansão, com geração de renda e emprego, principalmente ao longo da sua cadeia produtiva de transformação da madeira, incrementando a obtenção líquida de divisas para o país (Quadro 3). Se forem bem planejadas, as florestas plantadas podem representar investimentos atrativos para os produtores rurais, com ganhos semelhantes aos da agricultura, desde que bem planejadas antes da sua implantação.

Quadro 3 - Valor Bruto da Produção Florestal brasileira segundo os principais segmentos do setor.

\begin{tabular}{|l|c|c|}
\hline \multirow{2}{*}{ Segmento } & \multicolumn{2}{|c|}{ Valor Bruto da Produção Florestal (BRL Bilhões) } \\
\cline { 2 - 3 } & 2011 & 2012 \\
\hline Papel e Celulose & $30,8(57,3 \%)$ & $30,2(53,7 \%)$ \\
\hline Painéis de Madeira Industrializada & $5,3(9,9 \%)$ & $6,5(11,6 \%)$ \\
\hline Siderurgia e Carvão Vegetal & $2,2(4,1 \%)$ & $2,3(4,1 \%)$ \\
\hline Processamento Mecânico & $5,2(9,6 \%)$ & $5,8(10,3 \%)$ \\
\hline Energia & $10,3(19,1 \%)$ & $11,4(20,3 \%)$ \\
\hline Total & $53,8(100,0 \%)$ & $56,3(100,0 \%)$ \\
\hline
\end{tabular}

Fonte: ABRAF, 2013.

A indústria de floresta plantada mantém em Santa Catarina 85 mil hectares para preservação permanente e tem 111 mil hectares de florestas plantadas. As empresas do setor ainda fomentam o plantio em mais 30 mil hectares pertencentes a terceiros. No caso do eucalipto, o rendimento atual é de $41 \mathrm{~m}^{3} \mathrm{ha}^{-1} \mathrm{ano}^{-1}$, e estima-se chegar a $50 \mathrm{~m}^{3} \mathrm{ha}^{-1} \mathrm{ano}^{-1}$. $\mathrm{O}$ alto rendimento reduz a demanda por novas áreas para ampliação da produção. A produção anual de um milhão de toneladas de celulose no Brasil requer 100 mil hectares trabalhados (FIESC, 2014).

Dados da Associação Catarinense de Reflorestadores indicam que a produção brasileira de madeira em tora oriunda da silvicultura em 2014 , foi de $79 \%$ em madeira de 
Eucalyptus, estatísticas corroboradas pela ampla área de florestas com espécies de Eucalyptus no Brasil (ACR, 2016).

O Estado Catarinense em 2015, registrou a $4^{\mathrm{a}}$ maior produção de madeira em tora do Brasil, pois apresenta condições edafoclimáticas apropriadas para o desenvolvimento de florestas de pinus e eucalipto alcançando altos índices de produtividade, respondendo por $10 \%$ do total estimado produzido. A produção de toras de eucalipto representou $43 \%(9,9$ milhões $\mathrm{m}^{3}$ ) deste total (Figura 6).

Figura 6 - Evolução histórica da produção de madeira em Tora de florestas plantadas em Santa Catarina por destinação/uso (2006-2015) e participação por grupo de espécie (2014).
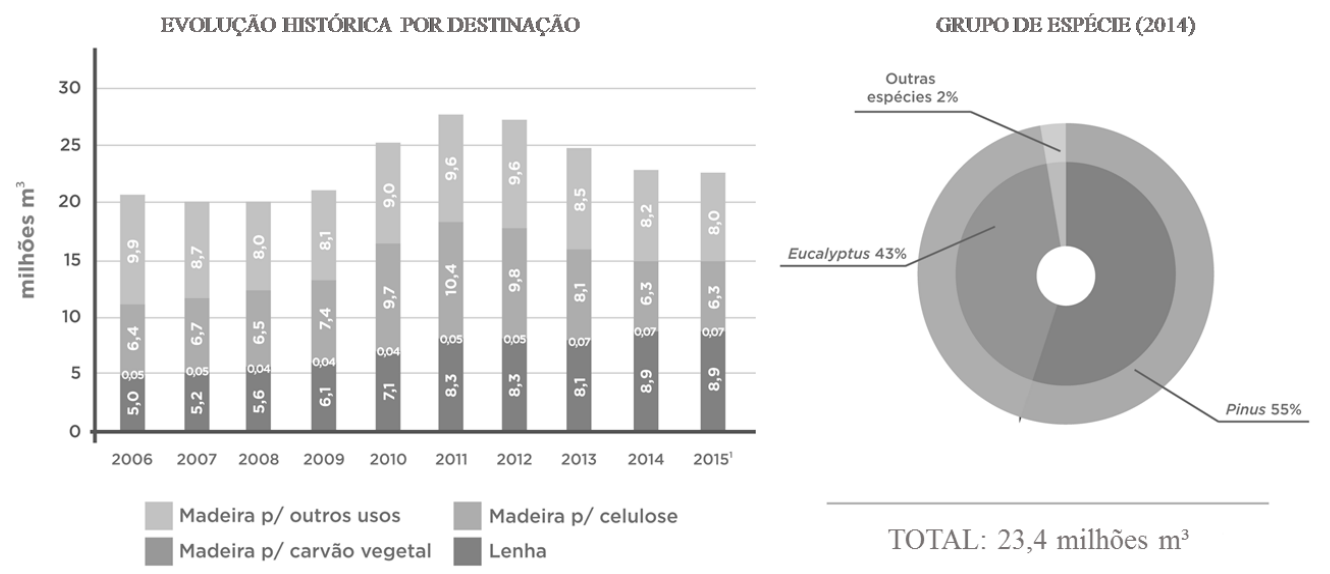

Fonte: ACR, 2016.

Em termos de utilização da madeira em tora no Estado no ano de 2015, se estima que 8,9 milhões $\mathrm{m}^{3}(38,2 \%)$ tenham sido destinados para fins de geração de energia (lenha), a qual atende diferentes segmentos industriais no estado (Figura 6). Observa-se ainda que a produção de madeira em tora para outros usos, tais como para serrado e lâminas, foi a segunda mais representativa em 2015 , equivalente a 8,0 milhões $\mathrm{m}^{3}(34,3 \%)$ frente às demais. Isso se deve ao fato da ampla gama de empresas ligadas ao uso de toras de maior diâmetro no estado, voltadas à produção de produtos de madeira sólida (ACR, 2016). A produção de energia e produção de papel e celulose a partir de matéria prima madeireira fomenta $\mathrm{o}$ crescimento em área de florestas plantadas no país. Ainda com relação as florestas plantadas conforme a ABRAF (2013), incrementos anuais significativos com Eucalyptus estão ligados à demanda futura dos projetos industriais do segmento de papel e celulose. Os autores Andrade Guerra et al. (2015), apontam a biomassa como uma possível fonte de energia renovável, principalmente com o aproveitamento de resíduos de outros processos de transformação, o que caracteriza um fator propulsor para o aumento de florestas plantadas. Ceccon e Miramontes (2008) afirmam que plantações florestais para a produção de biomassa têm um considerável impacto sobre as economias regionais no Brasil, envolvendo desde indústrias de grande escala como também pequenos agricultores. De acordo com os autores que a promoção de associações e parcerias florestais, contribuem significativamente para o aumento do mercado de trabalho e criação de novas fontes de renda, além de desempenhar importante papel na redução do desmatamento, na preservação do meio ambiente e na utilização mais 
racional dos recursos naturais. Outro produto das florestas plantadas, com destaque no Estado, é a lenha. Os autores Bendlin et al. (2014) comprovaram que plantios de eucalipto destinados à produção energética, bem como para indústria da madeira em toras constituem-se numa atividade rentável. Em 2011, foram produzidos mais de 8 milhões de metros cúbicos. Isso equivale a pouco mais de $16 \%$ de toda produção de lenha do país. Com relação ao carvão vegetal, a produção foi de pouco mais de 8 mil toneladas (Gráficos 1 e 2), representando 0,2\% de toda a quantidade de carvão vegetal produzida internamente no Brasil (PIRES, 2013).

Gráfico 1 - Uso de Madeira nos Municípios do PNC em 2006.

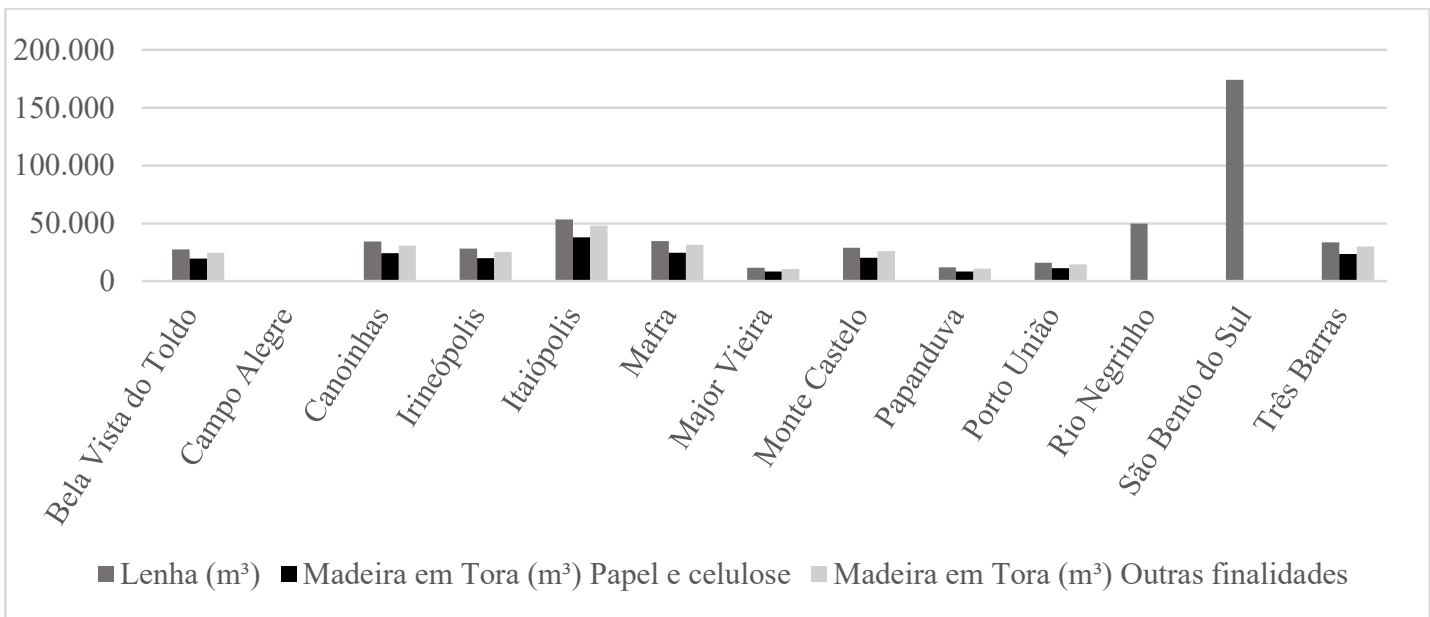

Fonte: IBGE, 2006.

Gráfico 2 - Valores (milhões de R\$) de produção dos segmentos madeireiros no PNC em 2006.

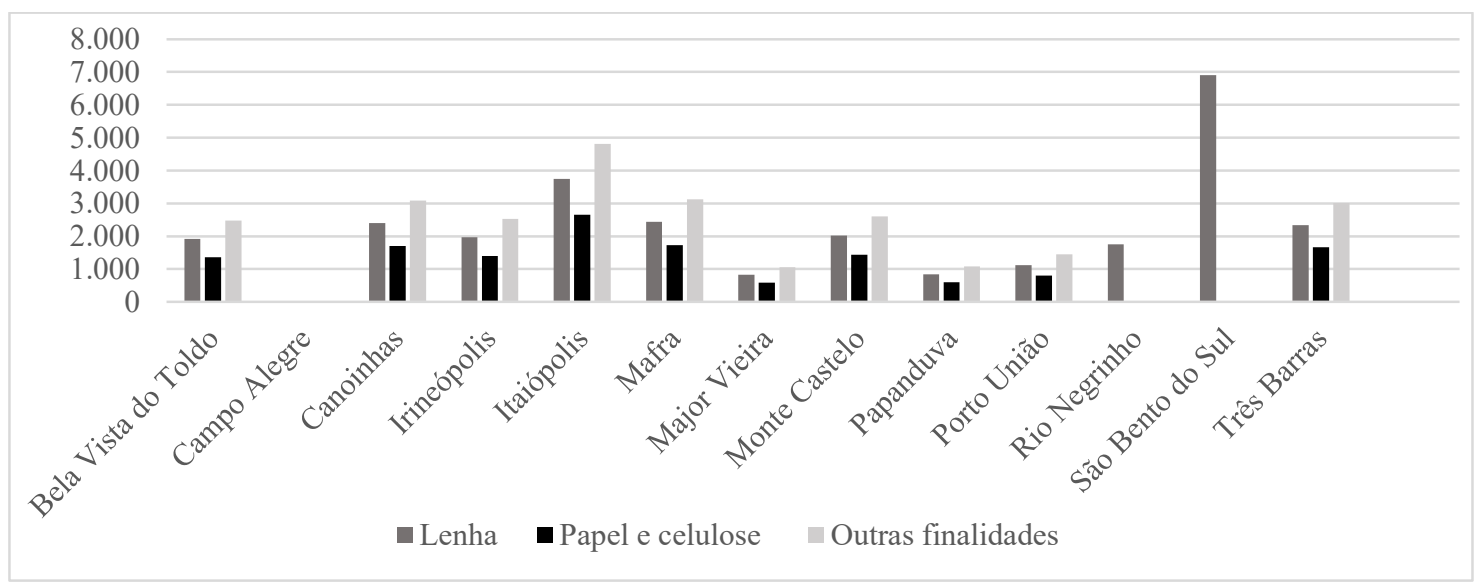

Fonte: IBGE, 2006.

Segundo a Sociedade Brasileira de Silvicultura (2011, p. 1) "cada hectare de floresta plantada de eucalipto produz a mesma quantidade de madeira que 30 hectares de florestas tropicais nativas". 


\subsection{INDICADORES SOCIAL E AMBIENTAL DO SETOR FLORESTAL EM SANTA CATARINA}

Atualmente os agentes públicos e privados passaram a incorporar em suas decisões de consumo e produção critérios ligados à preservação dos recursos naturais e isso representa uma grande mudança rumo ao desenvolvimento sustentável. Alternativas como: consumo energético de fontes renováveis (biomassa e gás natural), melhoria da eficiência energética, redução dos níveis de emissão de gases de efeito estufa, incentivo às certificações florestais, conservação da biodiversidade, estímulo aos serviços ambientais e aproveitamento dos resíduos e rejeitos que são gerados durante o processo produtivo, representam um diferencial no alcance de um desenvolvimento economicamente viável, socialmente justo e ambientalmente correto (GOMES et al., 2014).

Em 2012, quando o Brasil possuía apenas 6 milhões de hectares de florestas plantadas e 500 milhões de hectares de florestas nativas, Valverde (2012) afirmou que quase toda a riqueza sócio econômica do setor florestal vinha da silvicultura, ou seja, das plantações florestais. Para Santarosa et al. (2014), além de ser econômica e socialmente importante para o Brasil, as florestas plantadas, quando implantadas de maneira correta, têm papel essencial na qualidade de vida da população, pelos benefícios ambientais que proporcionam (conservação de solo, volume e qualidade de água, atenuação de efeitos climáticos negativos, como geadas e estiagem, manutenção da biodiversidade, entre outros).

Santarosa et al. (2014, p. 16) afirmam que:

O plantio florestal em pequenas e médias propriedades rurais com espécies de eucalipto, quando realizados de forma planejada e com o manejo adequado, contribui para a diversificação da produção e da renda. Além disso, é de interesse público, pois evita o êxodo rural e o desemprego, garantindo uma fonte de renda adicional aos produtores, concomitantemente com as demais atividades agropecuárias e, principalmente, auxilia na redução da pressão de desmatamento das florestas naturais remanescentes.

O eucalipto absorve grande quantidade de $\mathrm{CO}_{2}$ da atmosfera, o que diminui a poluição e combate o efeito estufa. Estima-se que 1 hectare de floresta sequestra anualmente 41 toneladas de $\mathrm{CO}_{2}$ (AGROLINK, 2009). O autor Bertola (2013), defende que o eucalipto, pelas suas características de adaptação às mais diferentes condições de clima e solo e diversificação do uso de sua madeira, tem sido uma das árvores mais plantadas no mundo, podendo ser considerado uma verdadeira 'árvore de negócios'.

Por definição do INCRA (2017, p. 1), é considerada pequena propriedade toda área de um a quatro módulos fiscais. A área do módulo fiscal varia de acordo com o município. Em todos os municípios do PNC o módulo fiscal tem área de 16 hectares, sendo considerada pequena propriedade áreas de 16 a 64 hectares. Segundo dados do EPAGRI (2016), o PNC detém cerca de 7,34\% das pequenas propriedades de todo o Estado e cerca de $85 \%$ dessas áreas são destinadas a agricultura familiar (Gráfico 3). 
Gráfico 3 - Uso do solo (ha) no PNC em 2006.

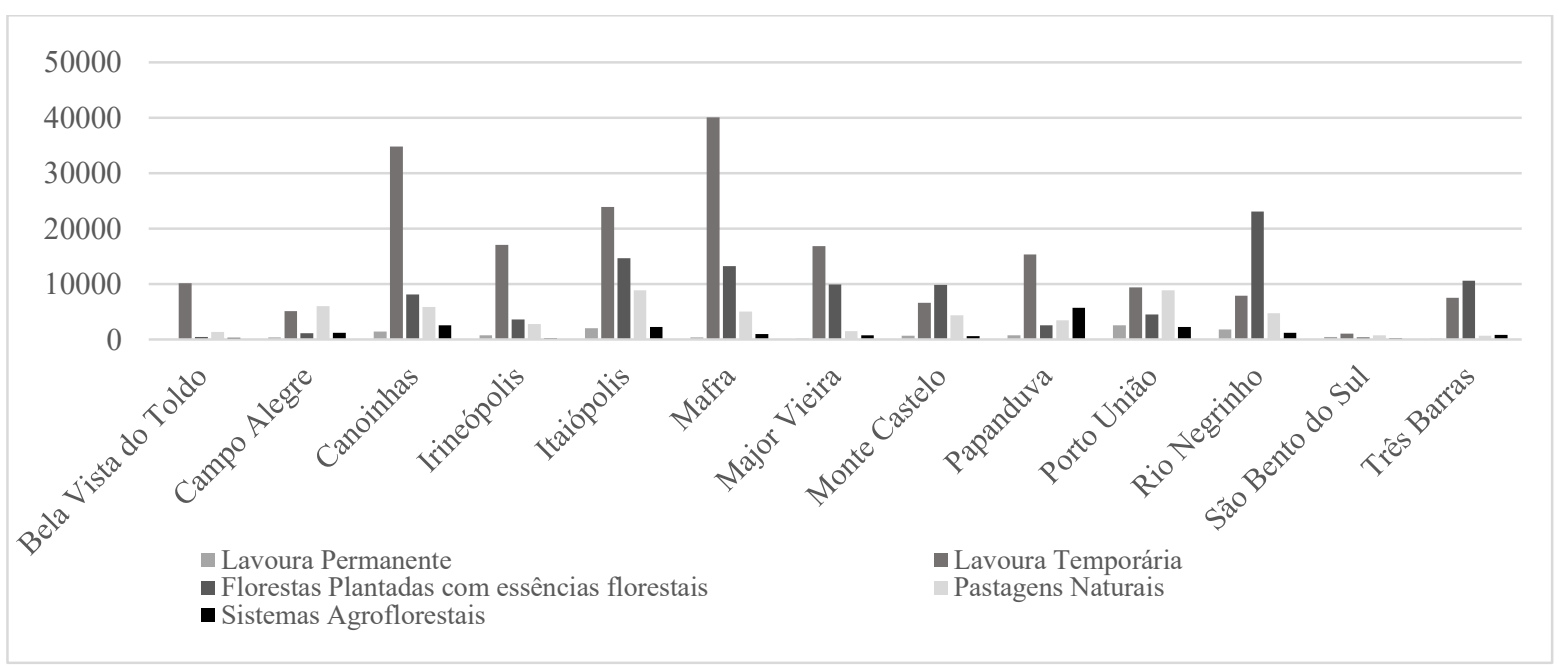

Fonte: IBGE, 2006

Uma alternativa de uso do solo para o pequeno produtor é a utilização de sistemas que integrem plantios florestais às atividades de lavoura e pecuária.

Para Santarosa et al. (2014, p. 16) [...]

\begin{abstract}
Os sistemas agrossilvipastoris, atualmente denominados também como sistemas de Integração Lavoura-Pecuária-Floresta (ILPF), são estratégias de uso da terra que permitem a diversificação da produção e renda na propriedade rural, visando sustentabilidade econômica, social e ambiental. Envolvem atividades agrícolas, pecuárias e florestais, realizadas na mesma área, em cultivo consorciado, em sucessão ou rotacionado.
\end{abstract}

Neste contexto, o ILPF possui vantagens não somente financeiras como também ambientais. O consórcio de culturas agrícolas com espécies florestais é benéfico devido a ciclagem de nutrientes, diminuição do efeito das variações climáticas na cultura agrícola, contenção de água no solo, atendimento da legislação compondo a reserva legal, entre outros. Estes sistemas auxiliam na recuperação do solo de áreas mal manejadas. Segundo IBGE em 2016, cerca de 0,34\% da área do PNC corresponde a pastagens degradadas e terras degradadas em geral (erodidas, desertificadas, salinizadas e etc...) (IBGE, 2017). No Gráfico 3 , quanto ao uso do solo, percebe-se o potencial para estes sistemas, uma vez que a maior parte do solo está coberta por lavouras temporárias.

Um grande desafio à sustentabilidade florestal está relacionado ao crescente aumento populacional mundial. Nesse âmbito, a partir do aumento da população e do consumo per capita, a FAO (citado por Relatório IBA 2015, p. 26) projeta que "a demanda por madeira para uso industrial e para geração de energia chegará a 5,2 bilhões de metros cúbicos por ano". Isto representa, um acréscimo de $40 \%$ de demanda nos próximos 35 anos (IBA 2015), o que exigiria o plantio adicional de cerca de 210 milhões de hectares de eucalipto em todo o mundo, considerando os níveis atuais de produtividade. Para suportar esse crescimento mundial, será necessário um esforço coletivo para aprimorar as técnicas de uso da terra, da água e dos demais recursos, conciliando a produção sustentável. 
Moreira et al. (2017) comentam que florestas plantadas de uso múltiplo, podem trazer desenvolvimento social e econômico, como emprego e renda, principalmente aos produtores rurais, com especial indicação as áreas degradadas, pela conversão destas em plantios florestais. O PNC destaca-se pela extensão de sua área florestal e por sua capacidade produtiva nesses termos e na geração dos produtos madeireiros. Knorek et al. $(2015$, p. 22) constataram que o setor florestal tem grande importância para o desenvolvimento econômico nos dois Territórios da Cidadania em Santa Catariana, sobretudo, nos aspectos econômicos e de acordo com as atividades de Produção Florestal [...] e [...] que muitos municípios dependem diretamente dessa atividade do setor florestal". Neste contexto, cabe salientar que as florestas plantadas poderiam oferecem uma gama de produtos e alguns serviços ecossistêmicos, que seriam os benefícios que a natureza nos proporciona direta ou indiretamente, por meio dos ecossistemas, sustentando a vida no planeta. Esse setor contribui para manter o equilíbrio dos ecossistemas naturais, pois o uso da floresta plantada promove a conservação da matas nativas. Auxilia na regulação do clima global e conservação dos recursos hídricos pela redução do nível de desmatamento ilegal e do impacto sobre as florestas nativas através da substituição por produtos originados em florestas plantadas. Ainda, regulariza o fluxo de água, protegendo e conservando o solo e consequentemente evitando erosão (BARROS JUNIOR, 2010). Ribaski et al. (2005, p. 6) citam que "[...] culturalmente, tem-se uma ideia incorreta de que 'o eucalipto seca o solo'. Inúmeros estudos já comprovaram que, no que diz respeito ao consumo de água e tolerância à seca ou a condições de déficit hídrico, existem respostas diferenciadas de acordo com cada cultura ou espécie plantada" (LIMA, 1996; MORA; GARCIA, 2000 apud RIBASKI, 2006, p. 6) e que outros resultados de pesquisa comprovam que o consumo de água de uma plantação de eucalipto é menor que o de outras monoculturas exóticas. Os autores Rezende et al. (2013) acreditam que o plantio do eucalipto em áreas degradadas pode contribuir para a sua recuperação e ainda atua, reduzindo o desmatamento das áreas nativas. Para Ribaski et al. $(2005$, p. 6) "[...] a introdução do componente florestal na propriedade, por meio dos sistemas silvipastoris (embora usando espécies exóticas), poderá contribuir significativamente para proporcionar maior estabilidade e proteção aos solos". Uma vez que, no passado a retirada maciça das florestas nativas comprometeu seriamente a biodiversidade, a manutenção de plantios florestais homogêneos, formando mosaicos junto às pequenas áreas de conservação de mata nativa, como as reservas legais e as áreas de preservação permanente, podem contribuir para a manutenção da biodiversidade de áreas naturais, quando encontram-se vizinhas. Pois os mosaicos permitem o fluxo de animais e de sementes, permitindo na manutenção do fluxo gênico tão importante para a manutenção da biodiversidade. Empreendimentos de produção florestal, desde que bem planejados, possuem um grande destaque no cumprimento legal na zona rural, pois estas propriedades rurais preservam as florestas nativas em reservas legais e em áreas de preservação permanente. Isso corrobora o discurso corrente de aliar o crescimento econômico à preservação dos recursos naturais.

Conforme Gabriel et al. (2013, p. 209),

\footnotetext{
Quanto ao manejo do eucalipto, observa-se que muitas empresas do setor florestal desenvolvem plantações em forma de mosaico: mantêm talhões e remanescentes distribuídos na paisagem e /ou mantêm talhões em diferentes idades, favorecendo a sobrevivência de espécies da flora e fauna de hábitos florestais e campestres em suas propriedades. Em algumas fazendas são encontrados plantios compostos por talhões de diferentes espécies arbóreas, que também podem beneficiar diferentes espécies, as quais seriam atraídas conforme características intrínsecas à árvore cultivada.
} 
Os indicadores de desenvolvimento humano relacionados à educação, longevidade, condições habitacionais, acesso ao trabalho, emprego e renda, e outras variáveis integram o IDH. Este indicador, para os municípios do Estado de Santa Catarina em 2010, destacava-se positivamente apresentando IDH médio de 0,774 . No PNC, onde as atividades de base florestal estão fortemente presentes, o IDH médio era 0,724 (ATLAS BRASIL, 2010) (Figura 7). Segundo dados da Bracelpa (2012) as atividades do setor estão presentes em 539 municípios, de 18 estados, e geram 115 mil empregos diretos (68 mil na indústria e 47 mil na base florestal) e 575 mil empregos indiretos.

Figura 7 - Indicadores de Desenvolvimento Humano Médio dos Municípios do Estado de Santa Catarina.

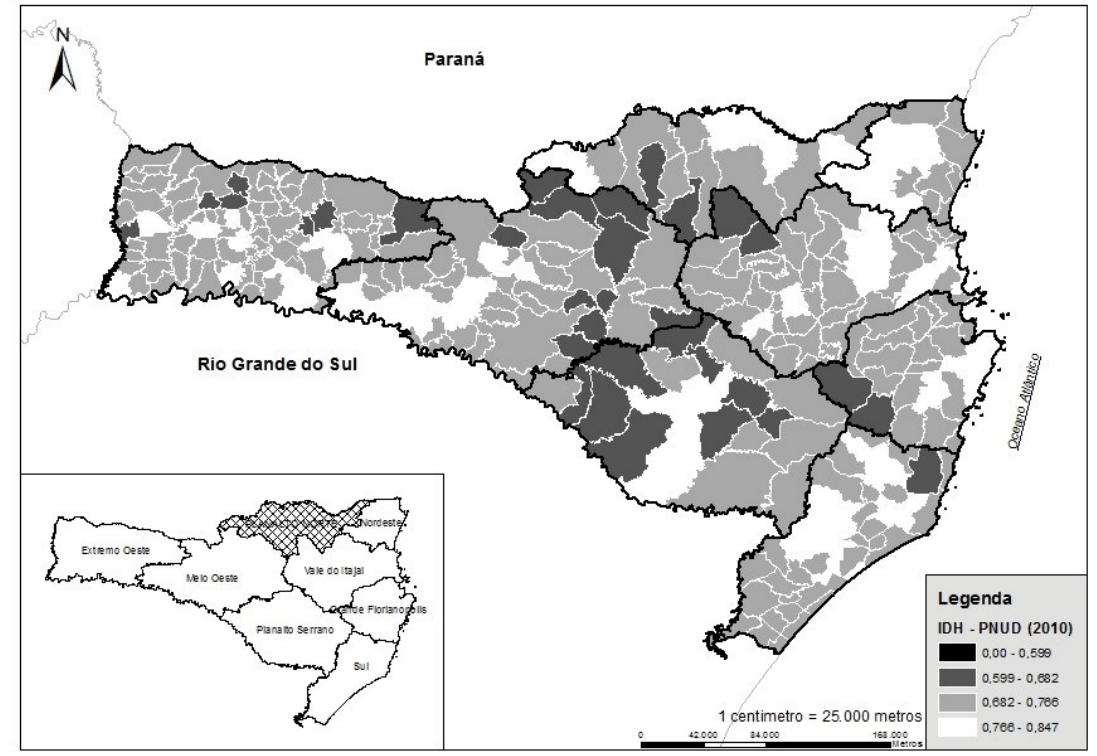

Coelho et al. (2016) em estudo na região do Alto Jequetinhonha, concluíram que reflorestamentos com eucalipto são uma alternativa viável para melhorar a qualidade de vida dos produtores rurais, absorvendo a mão de obra e promovendo melhoria da qualidade de vida. Também Cordeiro et al. (2016) comentam que em sistemas agrossilvipastoris o cultivo do eucalipto é rentável, mostrando-se altamente lucrativo.

\section{CONSIDERAÇÕES FINAIS}

Constata-se que o setor de florestas plantadas tem influência para o desenvolvimento econômico, social e ambiental do PNC, considerando-se que os aspectos econômicos refletem nos aspectos sociais, pela geração de renda, assim como na geração de empregos indiretos ligados ao setor, evidenciando que muitos municípios dependem diretamente dos setores de móveis, celulose e papel, serrados, extrativismo e silvicultura Entretanto é sabido que entender o desenvolvimento regional exigiria compreender além dos fatores e índices econômicos de fácil mensuração, buscar as evidências de melhoria da qualidade de vida e o 
entendimento de diversos fatores subjetivos, ligados a este fator. Desta forma, este manuscrito limitou-se a avaliação dos fatores identificados durante a pesquisa.

O aumento da área de silvicultura requerido para o futuro, leva a reflexão sobre as fragilidades e limites do setor florestal. Nesse sentido, será demandado não só a expansão da base florestal plantada, mas o estímulo a projetos inovadores na área de manejo florestal que busquem conciliar viabilidade técnica, legal e econômico-financeira. Outros desafios a serem superados referem-se à infraestrutura, tecnologia e questões sociais atreladas à produção florestal. $O$ investimento em capital humano e capital físico, mais especificamente na qualificação da mão de obra e na estrutura de produção serão necessários para crescimento do setor. Constata-se ainda que a atividade de silvicultura tem se mostrado economicamente viável, se bem planejada, com um amplo mercado a ser ocupado pois a procura pelos produtos florestais tende a ser maior do que a oferta existente.

A sustentabilidade do setor de florestas plantadas vem sendo fomentado por iniciativas ligadas principalmente ao desenvolvimento de tecnologias de melhoramento florestal e silvicultura, desenvolvidos pelas grandes corporações do setor. Com este enfoque, o melhoramento florestal tem identificado espécies mais adaptadas aos diferentes desafios edafoclimáticos, buscando maior produtividade e rendimento em menor área plantada. Já a silvicultura, por definição, deve promover a implantação e a regeneração dos povoamentos florestais, em função não apenas de interesses econômicos, mas também sociais, socioculturais e ecológicos. Neste sentido, as corporações do setor de florestas plantadas terão participação, demandada pelas exigências de órgãos certificadores, que incentivam ações de melhoria social e ambiental nas comunidades em que estão inseridas ou pela disponibilização da tecnologia de melhoramento genético/silvicultura nos programas de fomento. Iniciativas como estas teriam reflexo nos pequenos e médios produtores, ajudando a sua fixação no campo.

Como o setor florestal tem grande potencial a ser explorado e o PNC apresenta condições físicas e naturais para o desenvolvimento do mesmo, como elevada extensão de terras apropriadas, mão de obra abundante, clima e solo favoráveis, tecnologia silvicultural avançada e rápido crescimento das plantações florestais, o investimento na atividade florestal poderia contribuir para o desenvolvimento socioeconômico desta área. Esta afirmativa, provem de interesses econômicos, resguardados por políticas publicas de desenvolvimento, que favorecem a expansão das monoculturas florestais, em regiões de 'vocaçao florestal', mas estagnadas social e economicamente. Pois, sendo a atividade florestal uma atividade de retorno financeiro de longo prazo, sob o viés socioeconômico, o cultivo do eucalipto em monocultura apresenta-se como opção pouco atrativa aos agricultores, pois não oferece retorno de curto prazo como as culturas agrícolas. A identificação e qualificação das pequenas e médias propriedades no uso do ILPF poderia ser a ferramenta a ser utilizada para alavancar desenvolvimento, pois este sistema de produção, utilizando o eucalipto permitiria a diversificação de produtos e renda.

A premissa de que o crescimento econômico e a qualidade ambiental se equilibram atendendo o bem-estar presente sem comprometer as gerações futuras, considera que as questões socioambientais dependem de um desenvolvimento sustentável. Embora o eucalipto permaneça para alguns com o estigma de causar eventuais efeitos negativos sobre a biodiversidade, este mito se desfaz quando esta cultura surge como alternativa de preservação da natureza, pois estes ecossistemas também desempenham também funções ambientais, 
como aumento da infiltração das águas da chuva, redução da erosão, fonte de biomassa renovável ou contemplando as políticas de crédito de carbono, desta forma, diminuindo o impacto sobre as florestas nativas. As florestas plantadas podem contribuir para a conservação das florestas naturais, reduzindo a pressão sobre estes ambientes, possibilitando a conservação da biodiversidade. Pode-se citar ainda a regulação climática e dos fluxos hídricos, pelo fato de manter o solo ocupado, influenciando o regimes de chuvas pela absorção/ transpiração da água e a geração de energia renovável e limpa.

Atualmente, o mercado produtivo exige a conciliação entre a atividade econômica e a preservação do meio ambiente. Neste contexto, reconhecer e compreender as mudanças observadas demandarão esforços no que se refere à melhoria dos processos produtivos e à incorporação definitiva das questões ambientais na tomada de decisões. O verdadeiro desafio reside no estabelecimento de metas adequadas e inovadoras com políticas publicas voltadas ao desenvolvimento social e ambiental regional, que busquem viabilizar o desenvolvimento da população e o crescimento da produção para o atendimento da demanda esperada para o futuro.

Assim, uma opção de atividade rentável para os pequenos e médios produtores rurais, seria o plantio florestal sustentável, cultivando eucalipto prefencialmente em sistema ILPF, como uma alternativa para cumprir estas novas premissas ambientais e de produção. Para as políticas de desenvolvimento regional sustentável, o uso da eucaliptocultura se posiciona como atividade capaz de promover os tripés deste modelo de desenvolvimento, mostrando potencial alternativo para o uso diversificado do solo, nas zonas rurais do PNC.

\section{REFERENCIAS}

AGROLINK. Eucalipto é alternativa para reflorestar áreas devastadas. Agrolink. 2009. Disponível em: <www.agrolink.com.br/noticias/eucalipto-e-alternativa-para-reflorestar-areasdevastadas_97560.html $>$. Acesso em: 07 set 2017.

ABRAF. Associação Brasileira de Produtores de Florestas Plantadas. Anuário Estatístico da ABRAF 2013: ano base 2012. Brasília: ABRAF; 2013. Disponível em:

<www.ipef.br/estatisticas/relatorios/anuario-abraf13-br.pdf>. Acesso em: 19 maio 2017.

ACR. Associação Catarinense de Empresas Florestais. Anuário Estatístico de Base

Florestal para o Estado de Santa Catarina 2016 (Ano Base 2015). Lages, SC. 2016. Disponível em: <www.apreflorestas.com.br/wp-content/uploads/2017/03/ACR_AnuarioEstatistico-Florestal-ACR-2016.pdf>. Acesso em: 19 maio 2017.

ANDRADE GUERRA, J. B. S. O. et al. Future scenarios and trends in energy generation in Brazil: supply and demand and mitigation forecasts. Journal of Cleaner Production, v. 103, p. 197-210, 2015.

ATLAS BRASIL. Atlas do desenvolvimento humano no Brasil, 2010. Consulta. Disponível em: <http://www.atlasbrasil.org.br/2013/pt/consulta/>. Acesso em: 07 ago. 2017. 
BRACELPA Associação Brasileira de Celulose e Papel. Florestas plantadas: oportunidades e desafios da indústria brasileira de celulose e papel no caminho da sustentabilidade.

Confederação Nacional da Indústria, CNI. Cadernos setoriais rio+20. Brasília, 2012.

Disponível em: < https://static-cms-si.s3.amazonaws.com/media/filer_public/39/ad/39addf011c02-4c45-a962-978d782416f4/20131002175608453690i.pdf > Acesso em 11 out. 2017.

BARROS JUNIOR, A. A. Applications of heuristics in problems of forestry planning multiobjetivo. 2010. 82 f. Dissertação (Mestrado em Metodologias e técnicas da Computação; Sistemas de Computação) - Universidade Federal de Viçosa, Viçosa, 2010.

BENDLIN, L. et.al. Custos de produção, expectativas de retorno e riscos associados ao plantio de eucalipto na região do Planalto Norte - Catarinense/Brasil. Anais... XXI Congresso Brasileiro de Custos - Natal, RN, Brasil, 17 a 19 de novembro de 2014, p. 15.

BERNARDINO, J. L. Silvicultura de eucalipto: agentes da produção territorial na zona da mata mineira. 134 p. Dissertação (Mestrado em Geografia). Universidade Federal de Juiz de Fora, Juiz de Fora, 2015. Disponível em: http://www.gdimata.com.br/wpcontent/uploads/2017/07/Silvicultura-de-eucalipto-agentes-da-produção-territorial-na-zonada-mata-mineira.pdf>. Acesso em: 22 mar. 2018.

BERTOLA, A. Eucalipto - 100 anos de Brasil: "Falem mal, mas continuem falando de mim!". Setor de Inventário Florestal - V\&M Florestal Ltda, Curvelo - MG, 2013. Disponível em: <www.celso-foelkel.com.br/artigos/outros/Eucalipto_100\%20anos\%20 de\%20Brasil_Alexandre_Bertola.pdf $>$. Acesso em: 05 mar. 2017.

BROCKERHOFF, E. G., et al. Role of eucalypt and other planted forests in biodiversity conservation and the provision of biodiversity-related ecosystems services. Forest Ecology and Management, v. 301, p. 43-50, 2012. Disponível em: <www.dx.doi.org/10.1016/ j.foreco.2012.09.018>. Acesso em:19 out. 2017.

CECCON, E.; MIRAMONTES, O. Reversing deforestation? Bioenergy and society in two Brazilian models. Ecological Economics, v. 67, p. 311-317, 2008.

COELHO, R. M. et al. Avaliação econômica do uso da madeira de eucalipto para diferentes finalidades, na região do Alto Jequitinhonha, MG. Revista Floresta, v. 46, n. 2, p. 155-164, abr./jun. Curitiba. 2016.

CORDEIRO, S. A. et al. Simulação da Variação do Espaçamento na Viabilidade Econômica de um Sistema Agro florestal. Floresta e Ambiente. v. 25, n. 1, p. 2-8, 2016.

COUTINHO, V. M. et al. Mapeamento das áreas plantadas com Eucalyptus spp. No Estado do Paraná. BIOFIX Scientific Journal, v. 2 n. 1 p. 32-43, 2017.

DABA, M. The Eucalyptus Dilemma: The Pursuit for Socio-economic Benefit versus Environmental Impacts of Eucalyptus in Ethiopia. Journal of Natural Sciences Research. v.6, n.19, p. 127-137, 2016.

DALLABRIDA, V. R. et al. Indicação geográfica da erva-mate no território do contestado: reflexões e projeções. Desenvolvimento Regional em debate, v. 4, n. 2, p. 44-77, 2014. 
DALLABRIDA, V. R.; MILANI, M. L. Documento estratégico sobre desenvolvimento regional no Território do Contestado. Desenvolvimento Regional em debate, v. 6, n. 2, ed. esp., p. 26-33, jul. 2016.

ECONOMIA SC. Conheça o perfil Industrial catarinense por regiões. 2011. Disponível em: $<$ www.economiasc.com.br/conheca-o-perfil-industrial-catarinense-por-regioes $>$. Acesso em: 26 abr. 2017.

EPAGRI. Empresa de Pesquisa Agropecuária e Extensão Rural de Santa Catarina. Síntese Anual da Agricultura de Santa Catarina 2015-2016. Florianópolis: Epagri/Cepa, 2016. Disponível em: <www.docweb.epagri.sc.gov.br/website_cepa/publicacoes/

Sintese_2016.pdf $>$. Acesso em 11 out. 2017.

FIESC. Federação das Indústrias do Estado de Santa Catarina. Business Santa

Catarina/Brasil. Indústria, Parceiros e Oportunidades de Investimento. 2014. Disponível em: <www.2.fiescnet.com.br/web/pt/site_topo/publicacoes/info/business-santa-catarina-1 $>$. Acesso em: 11 out 2017.

FLORESTAL. Disponível em: <www.florestal.gov.br/snif/recursos-florestais/as-florestasplantadas>. Acesso em 29 maio 2017.

FRA. FOREST RESOURCES ASSESSMENT. FRA 2015: Terms and definitions, p. 3. Disponível: < http://www.fao.org/docrep/017/ap862e/ap862e00.pdf >. Acesso em 13 maio 2017.

GABRIEL, V. A. et al. A importância das plantações de eucalipto na conservação da biodiversidade. Pesquisa Florestal Brasileira, Colombo, PR, v. 33, n 74, p. 203-213, abr./jun. 2013.

GOMES, A. N. et al. Sustentabilidade de empresas de base florestal: o papel dos projetos sociais na inclusão das comunidades locais. Revista Árvore, Viçosa, MG, v. 30, n. 6, p. 951 960, 2006.

GOMES, F. P., et al. Crescimento econômico e demanda de recursos florestais no Brasil. 2014. Disponível em: < http://www.apec.unesc.net/VIII_EEC/sessoes_tematicas $>$. Acesso em 30 abr. 2017.

IBÁ. Indústria Brasileira de Árvores. Relatório IBÁ 2015. Disponível em: $<$ www.iba.org/images/shared/iba_2015.pdf>. Acesso em: 19 out.2017.

Indústria Brasileira de Árvores. Relatório IBÁ 2016. Disponível em:

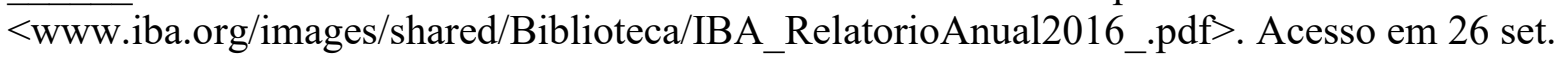
2017.

Indústria Brasileira de Árvores. Relatório 2017. Disponível em:

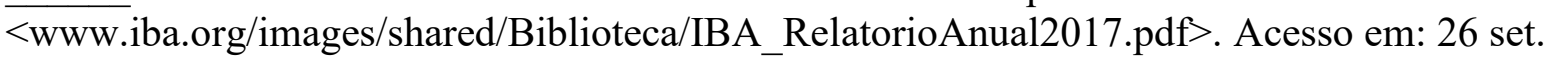
2017.

IBGE. Instituto Brasileiro de Geografia e Estatística. Mapa Dinâmico. Disponível em: <www.cidades.ibge.gov.br/brasil/sc >. Acesso em: 27 set. 2017. 
IBGE. Instituto Brasileiro de Geografia e Estatística. Censo Agropecuário 2006. Disponível em: $<$ https://ww2.ibge.gov.br/home/estatistica/economia/agropecuaria/censoagro/2006> Acesso em: 24 set. 2017.

INCRA. Instituto Nacional de Colonização e Reforma Agrária. Disponível em: <www.incra.gov.br/tamanho-propriedades-rurais>. Acesso em: 26 set. 2017.

KNOREK, R. et al. Território da cidadania em Santa Catarina: a importância econômica do setor florestal para o desenvolvimento territorial. Globalização em Tempos de Regionalização: Repercussões no Território. In: SEMINÁRIO INTERNACIONAL SOBRE DESENVOLVIMENTO REGIONAL, Santa Cruz do Sul, set. 2015. Anais... Santa Cruz do Sul, 2015.

LI, J.; LIU, H. The Study of the Ecological Problems of Eucalyptus Plantation and Sustainable Development in Maoming Xiaoliang. Journal of Sustainable Development. v. 3, n. 1, p. 197-201, 2010.

MOREIRA, J. M. M. A. P.; SIMIONI, F. J.; OLIVEIRA, E. B. Importância e Desempenho das Florestas Plantadas No Contexto do Agronegócio Brasileiro. Floresta, Curitiba, v. 47, n. 1, p. 85 - 94, jan./mar. 2017.

MOREIRA, P. O.; DALLABRIDA, V. R.; MARCHESAN, J. Processos de Territorialização, Desterritorialização e Reterritorialização (tdr): um estudo sobre a realidade socioeconômica no Planalto Norte Catarinense. Desenvolvimento Regional em debate, v. 6, n. 2, ed. esp., p. 88-103, jul. 2016.

PAYRET, C. C. Dinâmica de la matteria orgânica y de algunos parâmetros fisicoquímicos em molisoles, en la conversión de uma pradera a cultivo florestal em la regióan de Piedras Coloradas-Algorta (Uruguay). 2007. 273 f. (Doctorale en Sciences Agronomiques) - Institut National Polytechniqye de Toulouse, France, 2007.

PIRES, T. O Pinus e o setor florestal em Santa Catarina. 2013. Monografia. Universidade Federal de Santa Catarina. UFSC. Florianópolis, 2013.

PORTAL DA ECONOMIA DE SANTA CATARINA. 2017. Disponível em: $<$ www.novosite.fepese.org.br/portaldeeconomia-sc/index.php?c=dados $>$. Acesso em: 05 out 2017.

REZENDE, J. B.; PEREIRA, J. R.; BOTELHO, D. de O. Expansão da cultura do eucalipto nos municípios mineiros e gestão territorial. Revista Cerne, Lavras, v. 19, n. 1, p. 1-7, jan./mar. 2013.

RIBASKI, J. et al. Sistemas silvipastoris: estratégias para o desenvolvimento rural sustentável para a metade Sul do Estado do Rio Grande do Sul. Colombo: Embrapa Florestas, 2005. 8p. (Embrapa Florestas. Comunicado técnico, 150). Disponível em:

$<$ https://www.infoteca.cnptia.embrapa.br/bitstream/doc/312314/1/comtec150.pdf $>$. Acesso em: 22 mar. 2018. 
SANTAROSA, E.; PENTEADO JUNIOR, J. F.; GOULART, I. C. G. R. Transferência de tecnologia florestal: cultivo de eucalipto em propriedades rurais: diversificação da produção e renda. 1.ed. Colombo: Embrapa Florestas, 2014.

SEBRAE. Santa Catarina em números: tecnologia. Florianópolis: Sebrae/SC. 2010.

Disponível em: <www.sebrae.com.br/Sebrae/Portal\%20Sebrae/Anexos/

Relatorio\%20Estadual.pdf>. Acesso em: 07 set. 2017.

SIT. Sistema de Informações Territoriais. Disponível em: <www.sit.mda.gov.br $>$. Acesso em: 26 set. 2017.

SNIF. Sistema de Nacional de Informações Florestais. Cadeia Produtiva, 2017. Disponível em: <www.florestal.gov.br/snif/producao-florestal/cadeia-produtiva $>$. Acesso em: 19 jul. 2017.

SNIF. Sistema Nacional de Informações Florestais. 2016. Boletim de Recursos Florestais 2016, v. 1 e 2. Ed 2. Serviço Florestal Brasileiro. 2016. Disponível em:

$<$ www.florestal.gov.br/documentos/publicacoes/2232-boletim-snif-compilado-2016ed2/file>. Aceso em: 23 de jul 2017.

SOCIEDADE BRASILEIRA DE SILVICULTURA. 2011. Disponível em:

$<$ http://www.sbs.org.br/destaques_eucalipto_ciencia.htm>. Acesso em: 19 jul. 2017.

TOMPOROSKI, A. A.; MARCHESAN, J. Planalto Norte Catarinense: algumas considerações sobre aspectos históricos, características físico-naturais e extrativismo.

Desenvolvimento Regional em debate. v. 6, n. 2, ed. esp., p. 51-63, 2016.

VALVERDE, S. R. et al. Silvicultura brasileira: oportunidades e desafios da economia verde. Fundação Brasileira para o Desenvolvimento Sustentável (FBDS), 2012.

\section{Artigo recebido em: 10/11/2017}

Artigo aprovado em: 22/05/2018 